\title{
La participación de la creatividad en los procesos de apropiación de lo real
}

\author{
PARTICIPATION OF CREATIVITY IN THE PROCESSES OF APPROPRIATION OF THE REAL
}

Mg. María Inés Murrieta (mariainesasahi@yahoo.com.mx) Secretaría de Educación Pública (Ciudad de México, México)

Dr. Francisco Covarrubias (pancheco@prodigy.net.mx) Instituto Politécnico Nacional, Centro Interdisciplinario de Investigación para el Desarrollo Integral Regional (Unidad Michoacán) (Ciudad de México, México)

Ma. Guadalupe Cruz (lupitacruz63@hotmail.com) Instituto Politécnico Nacional, Centro Interdisciplinario de Investigación para el Desarrollo Integral Regional (Unidad Michoacán) (Ciudad de México, México)

\section{Abstract}

The aim of this work is to argue that creativity is given in all forms of consciousness and that could open new perspectives in the research of the processes of formation of subjects. The most important result is that all the forms of consciousness have an enormous diversity of referents of the different modes of appropriation of the real, they are provided of imagination and critical capacity and only in the artistic consciousness creativity is condition for its existence.

Key words: creativity, theory, art, religion, empirical.

\section{Resumen}

El objetivo de este trabajo es argumentar que la creatividad se da en todas las formas de conciencia y que esto puede abrir nuevas perspectivas en la investigación de los procesos de formación de sujetos. El resultado más importante es que todas las formas de conciencia disponen de una enorme cantidad de referentes de diferentes modos de apropiación de lo real, están dotadas de imaginación y capacidad crítica y sólo en la conciencia artística la creatividad es condición para su existencia.

Palabras clave: creatividad, teoría, arte, religión, empiria.

\section{Introducción}

La creatividad es predominantemente concebida como atributo del arte, tanto por los sujetos refinados como por los poseedores de conciencia ordinaria. La incursión en la teoría de los modos de apropiación de lo real y las formas de la conciencia de inspiración marxista, generó la duda de que la creatividad es de exclusividad artística, por ello se indagó en la estructura y condiciones en las que operan otras formas de la conciencia para determinar en ellas la presencia o ausencia de la creatividad. Se parte del principio de 
que el conocimiento de las condiciones en las que se genera y desarrolla la creatividad, pueden marcar las pautas pedagógicas para la formación de sujetos creativos.

La investigación consistió en el análisis de la literatura en la que se sustenta la teoría asumida y mostró que los sujetos solo pueden encauzar plenamente su creatividad en un solo tipo de actividad, a pesar de que para producir obras relevantes es necesario poseer referentes abundantes de los diferentes modos de apropiación de lo real. Otro resultado sorpresivo fue descubrir que, a pesar de que la capacidad crítica es condición necesaria para la creación, una vez que en la conciencia se instala una concepción construida con ella, el sujeto se resiste a abandonar sus concepciones y su criticismo parece desvanecerse.

Al final del trabajo se concluyó que la forma de una conciencia individual es determinada por los referentes de un modo de apropiación y se expone en dos apartados: en el primero se explica cómo se forma la conciencia individual y en el segundo se fundamenta el proceso de creación/re-creación y los elementos con los que el sujeto se apropia del objeto y re-crea lo ya creado con estructuras que lo hacen actual.

\section{La formación de la conciencia individual}

La conciencia individual se constituye con referentes emitidos por el aparato generador de conciencia (familia, escuela, internet, radio, televisión, partidos políticos, sindicatos), en un proceso en el que la conciencia individual es encarnación concreta de la conciencia social. Los órganos del aparato generador de conciencia generan y difunden referentes de diferentes modos de apropiación de lo real pero se especializan en los de uno de ellos, si bien predominan en todos ellos los correspondientes al modo empírico de apropiación.

El concurso de referentes de distintos modos de apropiación de lo real, da origen a la formación de la conciencia individual, la cual puede asumir una de sus cuatro formas: la práctico-utilitaria, la artística, la religiosa y la teórica. Las formas están definidas por los criterios con los que opera la conciencia y éstos son los del modo de apropiación predominante en el bloque de pensamiento constituido, debido a que a él pertenecen los referentes más potentes y abundantes.

Cada modo de apropiación se realiza bajo criterios exclusivos. Al modo religioso le son propias la divinidad, la santidad, la castidad, la obediencia, la encarnación, el mandato, etcétera; al teórico las categorías y los conceptos; al artístico los mensajes, las emociones, las figuras, los sonidos, etcétera; al empírico las experiencias práctico-utilitarias.

El objeto es apropiado a partir de los criterios predominantes en la conciencia, criterios que son los de uno de los modos de apropiación, a pesar de que ella pueda transitar de un modo a otro en diferentes momentos. Por ejemplo, Isaac Newton, considerado uno de los más grandes científicos de todas las épocas, fue un hombre profundamente religioso que para explicar las velocidades tangenciales de los planetas (lo que les impide caer en el Sol) recurrió al supuesto de que la mano de Dios los impulsó inicialmente. Los hechos posteriores a ese impulso - pensaba- podían ser explicados gracias a la ley de la gravitación universal (Russell 1951:39). También, parecía aceptar públicamente la creación repentina del Sol y de los planetas, gracias a la mano de Dios, aunque de manera privada comentaba la formación del sistema solar a partir de materia primitiva (Russell 1951:39).

La incorporación de referentes a la conciencia es permanente y mantiene a la conciencia en cambio permanente, pero sin mutar de forma, pues ésta se mantiene por largos periodos, que la mayoría de las veces, 
alcanza la totalidad de la vida del sujeto. Los referentes se incorporan al bloque de pensamiento con el código y la significación que establece la estructura de la conciencia constituida y no como fueron generados. Así se explica cómo referentes generados por el arte, la ciencia o la religión son incorporados pragmáticamente como datos en una conciencia ingenua.

Sin embargo, existen referentes intraducibles para determinadas conciencias individuales que son almacenados tal como llegan. Siguen almacenándose nuevos referentes que provienen del mismo modo de apropiación que los referentes no traducidos, hasta la llegada de uno que active la identidad de todos ellos y los articule en un modo de apropiación distinto al que predominaba en la conciencia o en una dinámica diferente dentro del mismo modo de apropiación, como sucede en el tránsito de una racionalidad a otra entre los filósofos y los científicos, o de un estilo a otro entre los artistas.

Podría pensarse que en cada uno de los sujetos sucede lo mismo que sucedió con Newton -es decir, pasar frecuentemente de la forma teórica a la religiosa o a la empírica-, pero no es así, pues solo sucede cuando el sujeto posee en abundancia los referentes de diferentes modos de apropiación.

La formación de los sujetos se da a lo largo de toda su vida y no solo inciden las instituciones tradicionales, sino que toda experiencia cotidiana puede ser apropiada por la conciencia y en esa apropiación puede estar implicada la creatividad. Sartre considera que en todas partes está el papel (el personaje) esperando a su hombre; para alguno, el papel de judío; para aquel el propietario de tierras, etc. (Sartre 1977:44). Las funciones las particulariza en familia y se le obliga a reencarnar por lo menos a un difunto. Así, el individuo muere en edad tierna víctima de sus parientes y sobrevive bajo la forma de un adulto: nuestro padre 0 madre, que son muertos vivientes. Apenas sale del vientre, cada hombre es tomado por otro, se le empuja, se le comprime para obligarle a entrar a la fuerza en su personaje. Así, el hombre es un niño robado, robado al mundo, robado a su prójimo y a sí mismo, porque mucho antes de nacer, al sujeto se le asigna un lugar y una situación a través de su familia. La conciencia del pequeño será el reflejo de ese lugar y de la situación generada en el seno familiar. En cada uno de los miembros, la conciencia social se ha condensado como conciencia individual, lo que facilita que el pequeño conforme su conciencia individual a partir de la educación familiar y con ello asuma la ideología dominante.

El niño aparece ahí dispuesto a recibir todo lo que le dé su medio. Ante sus ojos, está la realidad en toda su grandeza y complejidad, pero asumida desde la concepción del mundo que posee su familia, desde el lugar que socialmente le ha sido asignado. En esa fracción de la realidad hay miles de objetos, que se incorporan como referentes en el pequeño. Es en la familia donde el niño encuentra sus primeros referentes de los distintos modos de apropiación, aunque casi siempre traducidos al formato empírico.

Por ejemplo, un pequeño se encuentra por primera vez en contacto con un objeto al que los adultos llaman piedra. La toca, la huele, la pesa al apretarla con la mano y sacudirla, la chupa, la observa, la arroja. Comienza de esta forma a apropiarse de ella tomando en cuenta las experiencias que ya posee y las características de la roca. Puede ser que le atraiga su textura por ser completamente diferente a la de los objetos que hasta ese momento ha tocado, o su sabor por ser parecido al de la tierra que en varias ocasiones llevó a su boca, pero ésta es más dura, más grande y no se deshace al contacto con su saliva. Al arrojarla, no rebotó como los juguetes que tira constantemente, ni su madre la levantó para entregársela de nuevo, como lo hace con otros objetos. De esta forma, el niño se apropia del objeto piedra apoyándose en la información que él ha incorporado previamente y con los rasgos de esa roca. Así realiza una traducción del objeto roca a una idea, pudiendo con otros objetos hacer una traducción semejante a dato, idea, noción o imagen, es decir, crear un "referente", entendiendo por referente el resultado de un 
proceso de mediación social entre el concreto real (en este caso la roca) y la figura de pensamiento, por lo que todo referente es siempre el traslado de la conciencia social a la conciencia individual de formas específicas de concepción del mundo.

Esto significa que todo lo que el pequeño se apropia está en congruencia con aquello que la sociedad le ha permitido ver en el objeto a apropiarse, desde su nombre, hasta las cualidades que este objeto posee. Color, forma, tamaño, consistencia e incluso el nombre de esta roca están determinados de manera previa por la sociedad en la que el pequeño nace, pues el escenario está puesto antes de que el niño nazca. Incluso las actitudes son transmitidas de esta forma, pues, cuando el pequeño arrojó la piedra, su madre no se preocupó en dársela nuevamente, pues no tenía para ella ningún valor en ese momento. Entonces el infante reconocerá a ese objeto como innecesario. Tal vez, con el paso del tiempo, aprenderá que hay piedras que aunque pequeñas tienen algún valor y que serán guardadas con mucho cuidado: las piedras preciosas.

Los primeros referentes práctico-utilitarios que encuentra el niño en su vida son los que se activan en la vida familiar de manera sensorial; incluso, los referentes que se relacionan con la enseñanza moral, están determinados por la finalidad de las acciones a partir del deseo del otro y por la imitación de la conducta. El niño actúa en respuesta a un requerimiento sin que la reflexión intervenga y procede de un modo determinado porque desea evitar un castigo, recibir un premio, ser alentado y sobrevivir en el mundo de los adultos. Esto lo conduce a establecer el modo empírico de apropiación en su conciencia, por tratarse del modo predominante en la familia. El padre procede sin reflexión en su vida cotidiana y vive para trabajar y obtener un salario. La madre educa a los hijos utilizando el error y el acierto de manera práctica, aunque de manera creciente son organizaciones sociales distintas a la familia las encargadas de cuidar y educar a los hijos.

La familia, la escuela y los medios de comunicación, como instituciones del aparato generador de conciencia, cumplen su cometido en la conformación de la conciencia de todos los sujetos, incluyendo entre ellos a los sujetos creativos. La influencia negativa que estas instituciones tienen sobre el sujeto es atenuada por la forma de la conciencia del sujeto, ya que no existen referentes práctico-utilitarios, artísticos, religiosos o científicos en sí mismos, sino que son los criterios de apropiación del sujeto los que establecen esta relación con los referentes.

Los sujetos sociales tienen necesidades reclamantes de satisfacción. Entre la necesidad y su satisfactor media la actividad humana que es la que objetiva el pensamiento creador y la que finalmente entrega una creación a la humanidad con el trabajo. Gracias a él la creación toma la forma definida por la conciencia del creador, ya que, tanto la necesidad como la creación, están determinadas socialmente pues, dependiendo de la forma de conciencia será la necesidad generada, la acción realizada y el satisfactor de la necesidad, es decir, el objeto creado.

En la relación práctico-utilitaria, el sujeto trata de satisfacer una necesidad humana determinada y, por ello, valora los objetos por su utilidad o capacidad de satisfacerla. "En la relación teórica, [...] el conocimiento satisface la necesidad de afirmación real, efectiva del hombre ante la naturaleza. [...] La conquista de la objetividad implica el sacrificio de la subjetividad. [...] En la relación estética el hombre satisface la necesidad de expresión y afirmación que no puede satisfacer o satisface, en forma limitada, en otras relaciones con el mundo. En la creación artística, o relación estética creadora del hombre con la realidad, lo subjetivo se vuelve objetivo (objeto), y el objeto se vuelve sujeto, pero un sujeto cuya 
expresión ya objetivada no sólo rebasa el marco de la subjetividad, sobreviviendo a su creador, sino que ya fijada en el objeto puede ser compartida por otros sujetos" (Sánchez 1965:51-52).

Sánchez Vázquez no menciona la relación religiosa. En ésta, el sujeto trata de satisfacer necesidades espirituales que lo ponen en contacto con la divinidad, a la que desea complacer para recibir beneficios en esta vida o después de la muerte.

En el acto de creación, la acción que objetiva el pensamiento, es transformación de la naturaleza para afirmarse como humano. La búsqueda del satisfactor de la necesidad llevará al sujeto a crear. Es esta actividad la que diferencia al hombre de los animales, pues éstos sólo parten de lo dado como potencialidad, mientras que el hombre al crear satisface la necesidad sin limitarse a lo que la naturaleza le brinda. La necesidad surge sin tener un satisfactor materializado previamente. A través del trabajo el sujeto llega al acto de creación y lo creado permitirá la satisfacción de la necesidad. Conforme las necesidades son cubiertas, surgen nuevas necesidades que serán satisfechas por nuevas creaciones y lo creado generará nuevas necesidades.

Cuando algo interesa al sujeto se entrega a ese fin. Pone todo su ser para alcanzar su fin y la pasión es la energía que lo causa. El objeto interesa al sujeto porque es necesario para un fin y éste está determinado por la necesidad; la necesidad está condicionada socialmente al igual que el interés.

No es simple retórica la afirmación de que la humanidad se plantea los problemas que puede resolver y las metas que puede alcanzar. De igual manera, para obtener los resultados propuestos, los hombres no cuentan con los "instrumentos de producción" libre y arbitrariamente elegidos. El tejido social, con sus componentes económicos, políticos e ideológicos, decide en cada caso cuál es el arsenal del que se pueden valer (Pereyra 1984:14).

El interés mantiene al sujeto en la acción para crear un objeto que satisfará una necesidad. En la conciencia artística el interés aparece como síntesis de pasión y emoción encaminada a la expresión de la sensibilidad; en la conciencia religiosa, el interés es síntesis de pasión y creencia dirigida a la construcción del dogma y; en la conciencia empírica, el interés práctico-utilitario es la unión entre la pasión y la utilidad dirigida a la producción de inventos. Así, cada sujeto, de acuerdo a la forma de su conciencia, tiene diferentes intereses y objetos que los satisfacen.

\section{El proceso de creación/re-creación}

En cualquier proceso de creación la herencia cultural participa de manera activa. El sujeto nunca parte de la nada; en su conciencia siempre existen referentes sociales apropiados que lo constituyen indicándole el derrotero que habrá de seguir su práctica, aun en los casos de ruptura con el pasado.

Re-creación y creación son momentos diferentes del mismo proceso. Mientras el sujeto se apropia del objeto re-crea lo ya creado con estructuras que lo hacen actual. De este modo, el objeto es re-creado, destruido y construido nuevamente, por lo que ya no se trata del mismo objeto ni del mismo sujeto, aun cuando se repita lo previamente construido. En el proceso de creación/re-creación/creación el vínculo con el pasado es activo. El hombre es un sujeto que conforma su conciencia individual con la conciencia social, es decir, se forma del único modo posible en la sociedad en la que le toca constituirse, de ahí que sus prácticas creativas se den a partir de la determinación social de la que es objeto. Las construcciones 
originales están esbozadas en la realidad cambiante y son recogidas por el pensamiento que se las apropia, de ahí que sean unidad de pasado y presente condensado en un sujeto individual.

Los conocimientos, habilidades, destrezas, valores, intereses, voliciones, capacidades intelectuales y físicas, creencias y sentimientos que posee cada sujeto, son condensaciones individuales únicas diferenciales que hacen posible la comunicación refinada entre sujetos. Dice Nietzsche: "Todo ingenio distinguido y dotado de gustos distinguidos elige sus oyentes cuando quiere comunicarse, y al elegirlos se guarda de los demás. Todas las reglas sutiles del estilo tienen ahí su origen: alejan, crean distancia, prohíben la entrada o sea la comprensión, al par que abren los oídos de aquellos con quienes tenemos parentesco de oído" (1984:324).

Manuel Felguerez dice que la obra de arte es como un anzuelo que se lanza y pesca a aquellos que se fijan en él. Lo creado, en este caso, la obra de arte, entra en contacto con el hombre porque la constitución de su conciencia se lo permite. En la obra de arte el sujeto encuentra lo que la sociedad ha colocado en ella a través del trabajo del artista y en él a través de la conformación de su conciencia.

Es probable que un sujeto al establecer contacto con la obra de un artista se conmueva, reviva emociones, llegue a un estado de goce y placer, pero también puede suceder que el proceso se realice con criterios de otros modos de apropiación, si bien la creación no es exclusiva de uno de éstos. Apropiarse de un objeto es integrar al bloque de pensamiento los referentes que de él ha construido el sujeto; para lograrlo, pondrá en juego toda su experiencia, todo lo aprendido, sentido o reflexionado, re-creando las construcciones previas que la sociedad ha hecho del objeto. En la apropiación de un atardecer, el sujeto utiliza la información que ya posee como la intuición sensible de tiempo y espacio, el nombre de los colores, los sentimientos de placer, gusto o nostalgia sentidos previamente; observa el azul del cielo, el tono rojo amarillento de las nubes, el rojo intenso del sol, etc. Así, el sujeto llama atardecer al momento del día que todos Ilaman atardecer; azul, al color que todos Ilaman azul y amarillo al que todos Ilaman amarillo.

Estas convenciones no se reducen a la denominación de los fenómenos naturales, sino que alcanzan al sentimiento que genera ese momento del día. Así, el sentimiento que suscita un atardecer no es el mismo para un hombre del siglo XXI que visita Las Vegas en los Estados Unidos de Norteamérica y que quiere apostar o disfrutar de algún espectáculo, que para el hombre de las cavernas. Para el primero, puede significar la hora de regreso a la diversión, a la alegría, al despilfarro, a las apuestas. Para el hombre de las cavernas significó el temor intenso hacia los animales salvajes que salen a cazar de noche y para los cuales él es una presa más. Se trata pues de la existencia de criterios compartidos por una comunidad, que alcanza a los procesos de creación, generando una situación paradójica en la que, para crear, es necesario reproducir lo existente, en tanto que es necesaria la prexistencia colectiva de la idea de creación y de los criterios para su identificación.

Dice Hegel: "En efecto, el arte [...] reclama para cada género particular una particular capacidad. Se puede llamar talento a semejante disposición. Así, uno tiene talento, por el cual sobresale en la ejecución de un instrumento musical, otro ha nacido para el canto, etc. No obstante, [...] el simple talento no puede producir más que resultados de una hábil ejecución. [...] El talento sin genio no pasa de simple habilidad" (1946:118).

Para Hegel el genio es la capacidad para producir verdaderas obras de arte: "[El] genio tiene la facultad de elevarse a la ideas de Dios y llegar al conocimiento científico de las cosas. Para esto solo necesita haber nacido y haberse formado mediante la educación y el estudio. Pero otra cosa ocurre con el arte [...] el 
artista no debe elaborar su pensamiento solo con la inteligencia y la razón: su imaginación y sensibilidad deben intervenir al mismo tiempo" (1946:118).

Partiendo de esta idea, puede considerarse que en la creación están presentes el talento y el genio. Aunque Hegel considere que en la idea de Dios y el conocimiento científico de las cosas no están presentes la imaginación y el sentimiento, lo cierto es que ambas son consustanciales a la existencia del sujeto, independientemente de la forma que adquiera su conciencia. El talento, entendido como la capacidad para interpretar de manera puntual lo ya construido, da cuenta de aquellos sujetos que no crean pero que pueden expresar de manera magistral lo ya creado.

Como lo señala Arnold Hauser: "Toda obra de arte situada en una conexión histórica -y no conocemos ninguna fuera de esta conexión- muestra, junto a sus rasgos originales, rasgos también convencionales. La obra de arte tiene que utilizar medios de expresión conocidos y aprobados, no sólo para hacerse comprensible, sino incluso para poder acercarse a las cosas. El artista tiene que haber visto cómo se representa un objeto, para poder y querer representarlo. La vivencia individual e irracional tiene que someterse a una racionalización y convencionalización, a fin de salir de la esfera puramente personal y conservar algo de su sentido en el mundo de las relaciones interhumanas" (1994:3).

Es importante destacar que esta conexión histórica, este enlace con las generaciones precedentes y la contemporánea no siempre es consciente. El sujeto puede crear y considerar su obra completamente diferente a todas las demás, pero siempre utilizará elementos convencionales que se pondrán de manifiesto cuando otros sujetos se pongan en contacto con ella. Esto sucede con cualquier sujeto creador independientemente de la forma de su conciencia.

Si la intención del sujeto es la creación, necesariamente parte de lo creado para generar lo nuevo en la ciencia, el arte, la religión o la empiria. Lo ya creado cede su lugar a lo nuevo sin ser destruido pero sí transformado por el ejercicio de acciones producidas por la actitud crítica del sujeto, orientada hacia el objeto de interés. La capacidad crítica hace al sujeto activo y generador de cambio. Gracias al cuestionamiento detecta fallas e inconsistencias en el proceso de creación que lo colocan en la incertidumbre. Cualquier camino que siga es inédito. Sieber considera que la incertidumbre permite que el sujeto permanezca receptivo a toda la información que no corrobore la oportunidad de la decisión tomada y que gracias a ella es que se puede aprender de los errores, o bien, revertir decisiones insatisfactorias antes de que se haya causado un daño exagerado (Sieber 1971:136). Y aun encontrando los errores, el interés mantendrá al sujeto en la acción y la pasión seguirá dándole energía. La re-creación realizada permite recorrer el mismo camino hasta encontrar un punto en el cual se modifica, desechará completamente lo existente o construirá con varias ideas una nueva. Entre más cursos de acción tenga el sujeto, mayor será la construcción de ideas.

La crítica lleva a la detección de las fallas de lo construido y de lo que se está construyendo; no es propia de un momento determinado del proceso de creación, pues toda acción realizada para crear el satisfactor se va construyendo gracias a la crítica, haciendo interactuar lo construido con lo que se desea construir. El sujeto creador debe ser consciente de que las cosas no son como se conocen, ya que hay cientos de condiciones que jamás serán observadas en el objeto por su carácter cambiante.

El material para la creación es inagotable. La crítica se manifiesta cuando al apropiarse de referentes e integrarlos a la estructura del pensamiento, lo ya enunciado por otros no corresponde a lo que el sujeto ha podido estructurar, corresponda o no al concreto real al que se hace referencia. Gracias a la crítica, el 
individuo puede caminar por nuevos senderos y encontrar soluciones para apropiarse de lo ya existente, podrá obtener datos que no se conocían, desarrollar procedimientos y técnicas nuevas y hacer una nueva lectura del objeto. Con la crítica se confirma el sujeto como responsable de su pensamiento, se reconoce al conocimiento como producto del hombre en un momento histórico-social determinado y se penetra en la lógica con la que el objeto es explicado. La crítica es un fin y no un medio y el error posee un sentido positivo ya que es condición para el replanteamiento de lo apropiado.

La crítica está determinada por la lógica con la que el bloque de pensamiento opera y está definida por la forma de la conciencia del sujeto que la realiza, por lo que no es la misma crítica de un científico que la de un artista, un religioso o un sujeto práctico-utilitario. La crítica del sujeto con conciencia teórica se realiza mediante el cuestionamiento de los constructos teóricos que dan cuenta del concreto real; la conciencia práctico-utilitaria cuestiona la utilidad del objeto construido; la crítica de la conciencia religiosa se realiza con el cuestionamiento del dogma en relación con la creencia en la divinidad y la crítica de la conciencia artística se realiza con el cuestionamiento de la expresión de la sensibilidad del artista. Así, la forma de conciencia direcciona la crítica, los criterios aplicados y el resultado del proceso.

A la par de la intención de crear aparece la crítica y se pone en juego la reflexión, el razonamiento y la imaginación. Cuando la reflexión y el razonamiento son insuficientes para crear, la imaginación realiza combinaciones inéditas con referentes integrados en diferentes momentos y condiciones, que pueden modificar no únicamente los constructos de la conciencia, sino la forma misma en la que la conciencia opera. La imaginación permite combinar nociones, ideas, imágenes, datos, etc. que conducen a romper la rigidez del contenido y la forma de las figuras de pensamiento constituidas socialmente, así como la forma en la que el sujeto se apropia de los objetos. El sujeto, ya en su actividad creadora, puede experimentar impulsos para combinar imágenes con nociones, nociones con datos e ideas, imágenes con creencias y nociones, etc. generándose así una gama inagotable de combinaciones posibles e irrepetibles.

Vigotsky, al hablar de la tarea creadora, establece la diferencia entre dos tipos "fundamentales de impulsos": uno reproductor o reproductivo y otro creativo o combinador. El primero "suele estar estrechamente vinculado con nuestra memoria, y su esencia radica en que el hombre reproduce o repite normas de conducta creadas y elaboradas previamente o revive rastros de antiguas impresiones. Cuando rememoro la casa donde pasé mi infancia o países lejanos que visité hace tiempo estoy recreando huellas de impresiones vividas en la infancia o durante esos viajes. Con la misma exactitud, cuando dibujamos del natural, escribimos o realizamos algo con arreglo a una imagen dada, no hacemos más que reproducir algo que tenemos delante, que ha sido asimilado o creado con anterioridad. Todos estos casos tienen de común que nuestra actividad no crea nada nuevo, limitándose fundamentalmente a repetir con mayor o menor exactitud algo ya existente. [...] Además de la actividad reproductora, es fácil advertir en la conducta del hombre otra actividad que combina y crea. Cuando imaginamos cuadros del futuro, por ejemplo, la vida en el socialismo, o cuando pensamos en episodios antiquísimos de la vida y la lucha del hombre prehistórico, no nos limitamos a reproducir impresiones vividas por nosotros mismos. No nos limitamos a vivificar huellas de pretéritas excitaciones llegadas a nuestro cerebro, en realidad nunca hemos visto nada de ese pasado ni de ese futuro, y sin embargo, podemos imaginarlo, podemos formar una idea, una imagen" (Vigotsky 2002:11-13).

Por tal razón, es importante no confundir el proceso de creación (tarea creadora desde la perspectiva de Vigotsky), entendido como el proceso cuyo producto será algo nuevo, del proceso de recreación, del cual se vale el sujeto para apropiarse de lo ya construido. Ambos forman parte de un mismo proceso: el proceso de apropiación de lo real y en ambos la influencia natural y social son determinantes. 
Retomando el primer ejemplo: una piedra que se encuentra en algún lugar. La misma piedra al ser encontrada por diferentes sujetos, genera también diferentes conductas hacia ella. Uno de ellos la coloca en su mano, la observa, la mueve lentamente y las vetas atraen su atención, se fascina con sus colores, se siente complacido al mirarla y desea conservarla. Otro personaje la coloca en su mano, la mueve lentamente y piensa en la mano de Dios, en la grandeza del ser divino que ha creado todo lo existente a partir de la nada, y se siente afortunado porque Dios le ha permitido ver ese testimonio de su grandeza. Otro más se acerca a ella, la levanta, la observa y la coloca en una bolsa, pues aunque considera que es inadecuada para utilizarla en los cimientos de su casa, piensa colocarla como calza en la pata de un mueble que debido al desnivel del piso sobre el que se encuentra no queda estable. Por último, llega un hombre que observa la roca, con la uña de su dedo índice la talla y se pregunta qué tipo de minerales la componen, el porcentaje de sílice y carbonato que posee, la razón por la que este tipo de rocas predomina en esta región y la incluye a otras que llevará al laboratorio para estudiarlas.

Es increíble pensar en cómo esta pequeña roca habla de cada uno de los hombres que la toman, de la sociedad a la que pertenecen, así como de su formación y el lugar que ocupan en ella. Habla de las características que el individuo, aun sin tocarla, le ha plasmado. Es así como los hombres han humanizado los objetos, ya que pueden reconocer en ellos los colores y formas consideradas bellas (primer sujeto), las ideas religiosas del pueblo del cual provienen (segundo sujeto), la resistencia que se necesita en una construcción (tercer sujeto), e incluso las ideas del paradigma predominante en la comunidad científica de ese momento (cuarto sujeto).

Resulta interesante la relación que se establece entre el objeto y el sujeto que está construyendo sus referentes, que se está apropiando del mundo que le rodea ya que, gracias a la vida en sociedad, la relación va más allá de la simple satisfacción de las necesidades dirigidas a la conservación de la vida. Agnes Heller clasifica a las necesidades en naturales y socialmente determinadas. Las primeras son necesidades físicas o biológicas y permiten la conservación de las condiciones vitales. Las segundas son necesidades creadas por la sociedad (Heller 1986:28). Es decir, pasa de las necesidades físicas o biológicas a las necesidades creadas por la sociedad.

Los criterios utilizados en la apropiación de lo real no definen el tipo de combinación a realizar. Cabe recordar el ejemplo de Kekulé y la molécula de la estructura del benceno (Goleman 2000:33). Kekulé unió la racionalidad que prevalecía en su conciencia con una imagen propia del modo artístico de apropiación: "chispas bailando", "una serpiente mordiéndose la cola", rompiendo las fronteras impuestas por los modos de apropiación de lo real, pero manteniendo la hegemonía de uno de ellos en la forma teórica de su conciencia. Otro ejemplo es la expresión: "El ángel precedió al avión" (Jean 1990:65), donde se une el pensamiento religioso con el tecnológico, creando combinaciones a partir de las semejanzas entre dos o más cosas que se pensaban ajenas.

Como afirma Bronowski: "Todos los actos de la imaginación son así. Toman un sistema cerrado, lo inspeccionan, lo manipulan y entonces encuentran algo que hasta ese momento no había sido incluido en el sistema. Abren el sistema e introducen nuevas semejanzas, ya sea del tipo de Shakespeare cuando afirma My Mistres eyes are nothing like the Sunne o como Newton cuando sostiene que la luna se comporta igual que una manzana que hubiera sido arrojada al espacio. Aquello que imaginan cogen unas partes del universo que hasta entonces no habían sido conectadas y amplía la conectividad total del universo demostrando que lo están" (1981:123-124). 
Cuando se imagina, la construcción de la figura de pensamiento se realiza en algo que no necesariamente se encuentra ahí. Collingwood ejemplifica esto con una caja de fósforos de la cual muestra sólo tres caras y lo demás se puede imaginar permitiendo tener conciencia de la caja (1960:183). En algunas ocasiones, el sujeto críticamente combina sus referentes para encontrar en el pensamiento lo que no se percibe en un objeto 0 , inclusive, el objeto mismo. Lo pensado se puede objetivar o puede permanecer solo en la mente.

En el bloque de pensamiento la imaginación no pone límite a las combinaciones de referentes, aun tratándose de referentes sometidos a criterios de apropiación de diferentes formas de conciencia. Si la pasión hace que se mantenga el objeto en el pensamiento sin su presencia física, el sujeto puede relacionarse con el objeto estableciéndose una combinación de referentes inédita. Georges Jean señala: "la génesis de las funciones intelectuales es en realidad 'construcción de lo imaginario'. Y me inclino a decir que, para 'aprender a pensar bien' como decía Pascal, también hay que aprender a imaginar bien lo que al menos para mí no es ninguna paradoja” (Jean 1990:66).

La combinación que realiza la imaginación puede llevar al sujeto a imaginar, pero no siempre a crear. A veces, cuando se cuestiona esa combinación, la reflexión que se realiza lleva a concluir que lo pensado no satisfará la necesidad, por lo que el sujeto asumirá la crítica de lo pensado y de lo ya construido para detectar fallas y errores y nuevamente poner en juego su imaginación para generar combinaciones de referentes que satisfagan lo requerido y reflexionar sobre lo que se creó. Este proceso continuará hasta que la creación satisfaga la necesidad del sujeto. La combinación definitiva de referentes y los cambios a realizar son definidos por la conciencia a partir del modo de apropiación que domina en ella. Gracias a la imaginación, el sujeto combina ideas, nociones, categorías, imágenes, datos, teorías, etc. pero lo hace de conformidad con los criterios de apropiación que predominan en su conciencia. Este proceso libre en el bloque de pensamiento, vuelve al escrutinio de la crítica y permite al sujeto ponerse en acción para concretar su pensamiento.

Pero, a fin de cuentas, la imaginación, como base de toda actividad creadora, se manifiesta por igual en todos los aspectos de la vida cultural haciendo posible la creación artística, científica y técnica. En este sentido, absolutamente todo lo que nos rodea y ha sido creado por la mano del hombre, todo el mundo de la cultura, a diferencia del mundo de la naturaleza, es producto de la imaginación y de la creación humana, basado en la imaginación (Vigotsky 2002:13).

Kant plantea que según se relacionen las facultades de imaginación y entendimiento, serán las características que tome la creación; cuando predomina la imaginación, el sujeto expresa con mayor intensidad su subjetividad en la obra de arte, si predomina en la relación el entendimiento, la creación se vinculará a la ciencia (1991:285).

Esta relación define las creaciones de dos formas de conciencia: la artística y la científica. En el caso de la conciencia empírica que considera a la creación a partir de la utilidad que tiene para el fin que se propuso el sujeto, la imaginación combina los referentes pretendiendo encontrar el objeto que su pensamiento ha imaginado a partir de la utilidad que éste pueda tener. Así, todas las combinaciones que realice con los referentes que posee tendrán esa finalidad y los criterios aplicados de valoración de lo creado serán del mismo tipo. La acción del sujeto de esta conciencia se basa en el acierto y el error. Cuando haya error, la imaginación construirá nuevas combinaciones hasta que una de ellas se cristalice y satisfaga la necesidad que motivó al sujeto. Cuando se satisface la necesidad con un objeto que antes no existía, se está ante un producto de la creación empírica. 
En la conciencia artística, la creación está definida por la emotividad que el sujeto plasma en la obra, en cuya construcción la imaginación permite la combinación libre de referentes. Es en el arte en donde la combinación de referentes mayor libertad adquiere y donde la sensibilidad se objetiva en un objeto concreto: la obra de arte.

Aunque la imaginación existe en todos los modos de apropiación de lo real, no solo en el artístico, Hegel lo concibe de otro modo. Él considera que la actividad humana expresa el desenvolvimiento del espíritu absoluto y que, en ese despliegue del espíritu, aparece el "genio artístico" que es el único, desde la perspectiva hegeliana, que puede crear a partir del contacto con la realidad y no con generalizaciones abstractas.

El artista debe buscar la materia de sus creaciones en los inagotables tesoros de la naturaleza viviente y no en generalidades abstractas. El arte no es la filosofía; no es el pensamiento puro, sino la forma exterior de lo real lo que suministra los elementos de la producción. "Al conocimiento suficiente de las formas del mundo exterior, debe unirse el conocimiento de la naturaleza íntima del hombre, de las pasiones que agitan su corazón y de todos los fines a los cuales aspira su voluntad" (Hegel 1946:115).

Hegel considera que para el arte se necesita una disposición especial que sólo se da de manera innata; dice que el artista "no debe elaborar su pensamiento sólo con la inteligencia y la razón: su imaginación y sensibilidad deben intervenir al mismo tiempo" (1946:118). En esta frase, Hegel limita la imaginación y la sensibilidad al ámbito del arte y esta idea ha sido compartida por otros.

En la conciencia religiosa se considera al objeto creado a partir de la creencia en la divinidad. En ella la imaginación juega un papel preponderante, ya que se prescinde completamente del objeto físico para realizar combinaciones con los referentes existentes, hasta generar un objeto nuevo que dé cuenta del dogma. La creación puede ir en dos sentidos: 1) el elemento ideal, considerado como la existencia inmaterial de poderes más grandes que los del hombre y 2) el elemento práctico vinculado a la cotidianidad para complacer a esos poderes. El objeto que buscan crear puede manifestarse en cualquiera de estos aspectos, pero siempre pretenderá dar cuenta del dogma y será guiado por la fe y la creencia en ese poder superior o divinidad. Este será el criterio para valorar la pertinencia de la nueva creación, la cual mantendrá la relación con la divinidad ya sea en lo ideal o en lo práctico.

En el caso de la conciencia teórica que considera que la realidad puede ser conocida a través la razón, la imaginación permite la combinación de referentes teóricos con otros procedentes de modos distintos de apropiación. La combinación de referentes realizada permite crear una nueva teoría, descubrir una ley de la naturaleza, conocer los concretos reales.

Marx al hablar del arte griego y la sociedad moderna, considera que "es en la imaginación y por la imaginación que la mitología supera, domina y modela las fuerzas de la naturaleza: desaparece por tanto cuando, en realidad, estas fuerzas son dominadas" (1988:57). Y continúa diciendo que: "Lo difícil no es comprender que el arte griego y la epopeya están ligados a ciertas formas de desarrollo social sino que nos aseguran también un placer estético y, en muchos respectos, representan para nosotros una norma, incluso un modelo inaccesible. [...] El encanto que nos inspiran sus obras no sufre del débil desarrollo de la sociedad que las hizo florecer: ellas son más bien el resultado inseparable de las condiciones de inmadurez social en que este arte nació, en que sólo podía nacer y que no volverá nunca más" (1988:5758). 
Marx establece que a cada sociedad corresponde determinado arte; si el arte es considerado creación, a cada sociedad corresponde determinada creación dado que nace en determinadas condiciones sociales que no se darán nunca más. De igual forma se puede afirmar que a cada sociedad corresponde un determinado tipo de imaginación y que ésta es propia de ese momento histórico por lo que no se repetirá jamás.

Es un hecho que la naturaleza se encuentra en transformación continua, por ello, la explicación que muestra la objetividad del pensamiento nunca terminará de construirse y el hombre como naturaleza socializada nunca terminará de transformarse. Las creaciones actuales: teorías, obras, inventos, etc. que satisfacen las necesidades materiales y espirituales del hombre de hoy, pronto dejarán de hacerlo ya que siempre está cambiando.

\section{Conclusiones}

De lo analizado en este trabajo se puede concluir que la conciencia individual se constituye con referentes provenientes de distintos modos de apropiación de lo real, pero son los referentes de uno de esos modos los que establecen la forma en la que esa conciencia opera. El modo de apropiación que predomina en la conciencia determina la forma de ésta y somete a su dinámica los referentes provenientes de otros modos de apropiación. En todas las formas de la conciencia participa la creatividad pero es imprescindible en la forma artística y puede existir en sujetos en los que se encarnan las formas empírica y religiosa. En los procesos creativos se activan referentes provenientes de distintos modos de apropiación, a pesar del predominio de uno de ellos en la conciencia y en todos está presente la crítica y la imaginación. Queda sin resolver por qué la conciencia fija la concepción con la que ejerció su criticidad y la condujo a la creación.

\section{Financiamiento}

Este artículo es parte del Proyecto IPN-SIP 20140649, titulado "Sensación, representación y construcción racional".

\section{Bibliografía}

Bronowski, J. 1981. Los orígenes del conocimiento y la imaginación. Barcelona: Gedisa.

Collingwood, R. G. 1960. Los principios del arte. México: Fondo de Cultura Económica.

Goleman, D. et al. 2000. El espíritu creativo. Buenos Aires: Javier Vergara.

Hauser, A. 1994. El lenguaje del arte. Educación Artística 6: 3-7.

Hegel, G. W. F. 1946. De lo bello y sus formas. Buenos Aires: Espasa-Calpe.

Heller, A. 1986. Teoría de las necesidades en Marx. Barcelona: Península.

Jean, G. 1990. Los senderos de la imaginación infantil. Los cuentos. Los poemas. La realidad. México: Fondo de Cultura Económica.

Kant, I. 1991. Crítica del juicio. México: Porrúa.

Marx, K. 1988. El método en la economía política. México: Grijalbo.

Nietzsche, F. 1984. La gaya ciencia. México: Editores Mexicanos Unidos. 
Pereyra, C. 1984. El sujeto de la historia. Madrid: Alianza Editorial.

Russell, B. 1951. Religión y ciencia. México: Fondo de Cultura Económica.

Sánchez, V. A. 1965. Las ideas estéticas de Marx. México: Era.

Sartre, J. P. 1977. Literatura y arte. Buenos Aires: Losada.

Sieber, J. E. 1971. Lecciones de incertidumbre. En: R. D. Strom. Creatividad y educación. Buenos Aires: Paidós.

Vigotsky, L. S. 2002. La imaginación y el arte en la infancia. Ensayo psicológico. México: Ediciones Coyoacán.

Recibido el 14 Dic 2014

Aceptado el 25 Abr 2015 